\title{
Four-dimensional flow magnetic resonance imaging study to explain high prevalence of pulmonary vein stump thrombus after left upper lobectomy
}

\author{
Tadashi Umehara ${ }^{1}$, Koji Takumi ${ }^{2}$, Kazuhiro Ueda ${ }^{1}$, Takuya Tokunaga ${ }^{1}$, Aya Harada-Takeda ${ }^{1}$, \\ Soichi Suzuki ${ }^{1}$, Masami Sato ${ }^{1}$ \\ ${ }^{1}$ Department of General Thoracic Surgery, Kagoshima University Graduate School of Medical and Dental Sciences, 8-35-1 Sakuragaoka, Kagoshima, \\ Japan; ${ }^{2}$ Department of Radiology, Kagoshima University Graduate School of Medical and Dental Sciences, 8-35-1 Sakuragaoka, Kagoshima, Japan \\ Contributions: (I) Conception and design: T Umehara, K Takumi, K Ueda, M Sato; (II) Administrative support: None; (III) Provision of study \\ materials or patients: None; (IV) Collection and assembly of data: T Tokunaga, A Harada-Takeda, S Suzuki, M Sato; (V) Data analysis and \\ interpretation: All authors; (VI) Manuscript writing: All authors; (VII) Final approval of manuscript: All authors. \\ Correspondence to: Kazuhiro Ueda, MD, PhD. Department of General Thoracic Surgery, Kagoshima University Graduate School of Medical and \\ Dental Sciences, 8-35-1 Sakuragaoka, Kagoshima 890-8520, Japan. Email: k7433286@kadai.jp.
}

Background: Pulmonary vein (PV) stump thrombus, a known source of cerebral infarction, develops almost exclusively after left upper lobectomy; however, the mechanism remains unclear. We therefore evaluated the hemodynamics in the left atrium with four-dimensional flow magnetic resonance imaging (4D-flow MRI), which enables the simultaneous depiction of blood flow at three locations and the evaluation of hemodynamics.

Methods: 4D-flow MRI was basically performed 7 days after lobectomy for cancer arising in the right upper lobe $(n=11)$, right lower lobe $(n=8)$, left upper lobe $(n=13)$, or left lower lobe $(n=8)$. We evaluated dynamic blood movement from the ipsilateral remaining PV, the resected PV stump, and the contralateral PVs into the left atrium using 4D-flow MRI.

Results: There were some characteristic blood flow patterns that seemed to either promote or prevent PV stump thrombus. Promotive flow patterns were significantly more frequent and preventive flow patterns were significantly less frequent in patients who had undergone left upper lobectomy than in those who had undergone other lobectomy. Accordingly, the degree of blood turbulence near the vein stump, as measured by the extent of change in the blood movement, was significantly higher in patients who had undergone left upper lobectomy than in patients who had undergone other lobectomy.

Conclusions: Our study revealed that left upper lobectomy likely causes blood turbulence near the vein stump through complicated blood streams in the left atrium, which can play a part in the development of vein stump thrombus. Further study to identify patients at high risk of vein stump thrombus is warranted.

Keywords: Four-dimensional flow magnetic resonance imaging (4D-flow MRI); lung cancer; pulmonary vein thrombus

Submitted Apr 07, 2020. Accepted for publication Aug 19, 2020.

doi: $10.21037 /$ jtd-20-1606

View this article at: http://dx.doi.org/10.21037/jtd-20-1606 


\section{Introduction}

Since Ohtaka et al. reported the frequent occurrence of pulmonary vein (PV) stump thrombus after left upper lobectomy in 2013 (1), many clinicians treating lung cancer have paid attention to this adverse condition. In accordance with the Ohtaka's report (1), PV stump thrombus was exclusively found after left upper lobectomy or left upper division segmentectomy (2). Based on the fact that postoperative cerebral infarction predominantly develops after left upper lobectomy (3), many clinicians attempted to clarify the pathogenesis and preventive measures that are effective against PV stump thrombus. Some clinicians speculated that the exclusive onset of PV stump thrombus after left upper lobectomy could be attributed to the significantly longer length of the PV stump after left upper lobectomy in comparison to after any other lobectomy $(1,4,5)$. Unfortunately, although surgeons have attempted to reduce the length of the PV stump after left upper lobectomy by proximal ligation, PV stump thrombus was still found to develop in a proportion of patients after left upper lobectomy $(4,5)$. Because it appeared to be difficult to explain the pathogenesis of PV stump thrombus by simple anatomical evaluation of the PV stump, further studiesincluding dynamic studies-may be necessary to evaluate the blood flow in the left atrium or PV stump, to investigate the presence or absence of blood stasis or turbulence that may contribute to thrombus formation. Recently, fourdimensional flow magnetic resonance imaging (4D-flow MRI) played a significant role in visualizing dynamic blood flow in patients with major cardiovascular diseases (6), without need for radiation exposure or the usage of contrast agents. 4D-flow MRI also contributed to obtaining hemodynamic parameters, such as blood flow and flow rate in any section of the cardiovascular system (7). This modality revealed detailed hemodynamic properties in patients who had undergone endovascular stenting for aortic aneurysm (8) or aortic valve replacement for aortic valve stenosis (9). Importantly, this modality enables the simultaneous depiction of three different blood flows, which may be advantageous to evaluate interaction among blood streams from individual PVs. We performed dynamic studies of patients who had undergone lobectomy, using 4D-flow MRI to depict the blood streams in three different locations: the ipsilateral remaining $\mathrm{PV}$, the contralateral PV, and PV stump. The aim of the present study was to clarify the features of the hemodynamics in the left atrium and PV stump after lobectomy in order to explain the high prevalence of PV stump thrombus after left upper lobectomy. We present the following article in accordance with the STROBE reporting checklist (10) (available at http://dx.doi.org/10.21037/jtd-20-1606).

\section{Methods}

\section{Patients}

The present case-control study included 40 patients who had undergone lobectomy [upper lobectomy $(n=13)$, left lower lobectomy $(n=8)$, right upper lobectomy $(n=11)$, and right lower lobectomy $(n=8)]$, in our institution from November 2017 to May 2019. To exclude the effect of cardiac functional variability on the pulmonary venous flow, patients with the following conditions were excluded: ejection fraction $(\mathrm{EF})<50 \%$, grade $\geq$ III mitral valve regurgitation, asynergy in the ventricles, and atrial fibrillation. This study was conducted in accordance with the Declaration of Helsinki (as revised in 2013). The study was approved by our institutional review board of No. $190046 \mathrm{E}$ and informed consent was taken from all the patients.

4D-flow MRI was basically performed on the postoperative day 7 , along with the methodologies described below. The characteristics of the patients are shown in Table 1. Some patients had underlying diseases, such as hypertension and diabetes mellitus. However, no patients had blood coagulopathy or vascular endothelial dysfunction. None of the patients were treated with anticoagulants. Lobectomy was performed due to primary lung cancer $(n=37)$, metastatic lung tumor $(n=2)$, or benign lesion $(n=1)$. We also obtained 4D-flow MRI images in three additional patients with primary lung cancer before surgery to evaluate the blood flow patterns in the left atrium.

\section{Operation}

The operation was performed via 4 port sites $(n=26)$ or open thoracotomy $(n=14)$ under general anesthesia with endobronchial intubation. We used an endoscopic stapler (Ethicon, Cincinnati, OH, USA; or Covidien, Minneapolis, MN, USA) to divide the fused fissures as well as the pulmonary artery, vein or bronchus. During the early study period, postoperative PV stump thrombus occurred in two of the six patients who had undergone left upper lobectomy. Thus, in the latter half of the study period, we performed proximal ligation of the left superior PV before stapling the 
Table 1 Characteristic variables according to the site of resection

\begin{tabular}{|c|c|c|c|c|}
\hline Variables & Total & \multicolumn{2}{|c|}{ Operation } & $P$ \\
\hline Number & 40 & 13 & 27 & \\
\hline Age (years) & $71.0 \pm 7.7$ & $67.8 \pm 10.8$ & $71.5 \pm 5.7$ & 0.17 \\
\hline Gender (M/F) & $17 / 33$ & $5 / 8$ & $12 / 15$ & 0.72 \\
\hline Primary cancer & 37 [93] & 13 [100] & 24 [89] & \\
\hline Metastatic & $2[5]$ & $0[0]$ & $2[7]$ & \\
\hline Benign & $1[2]$ & $0[0]$ & $1[4]$ & \\
\hline \multicolumn{5}{|l|}{ Underlying diseases } \\
\hline \multicolumn{5}{|l|}{ Cardiac ultrasound } \\
\hline $\mathrm{EF}(\%)$ & $69.0 \pm 6.5$ & $69.0 \pm 3.2$ & $68.9 \pm 7.8$ & 0.96 \\
\hline Asynergy (yes/no) & $3 / 37$ & $0 / 13$ & $3 / 24$ & 0.21 \\
\hline $\operatorname{MR}(0 / 1 / 2)$ & $7 / 21 / 12$ & $4 / 6 / 3$ & $3 / 15 / 9$ & 0.30 \\
\hline Approach (port access/open) & $26 / 14$ & $6 / 7$ & $20 / 7$ & 0.08 \\
\hline Dissection of pulmonary vein (ligation/stapling) & $7 / 34$ & $7 / 6$ & $0 / 27$ & $<0.0001$ \\
\hline Node dissection (hilar/mediastinal) & $9 / 31$ & $2 / 11$ & $7 / 20$ & 0.45 \\
\hline Operation time (min) & $250 \pm 104$ & $312 \pm 142$ & $247 \pm 77.5$ & 0.07 \\
\hline
\end{tabular}

Values are expressed as number or mean \pm SD. EF, ejection fraction; MR, mitral valve regurgitation; LUL, left upper lobectomy; others, other operation including left lower lobectomy $(n=8)$, right upper lobectomy $(n=11)$, and right lower lobectomy $(n=8)$.

left superior PV in seven patients. We basically performed mediastinal lymph node dissection in a lobe-dependent manner (upper mediastinal dissection for upper lobe disease, and lower mediastinal dissection for lower lobe disease) for patients with primary lung cancer.

\section{MRI technique}

All magnetic resonance examinations were performed using a 1.5- and 3-Tesla system (Aera and Prisma, Siemens Healthcare, Erlangen, Germany) with a 30-channel body array coil. Prospective electrocardiography-gated 3D phase-contrast MRI with 3-directional velocity encoding (4D-flow MRI) was acquired using a coronal oblique volume covering the heart. The magnetic resonance scan parameters were as follows: flip angle, $8^{\circ}$; echo time (TE),
2.5-3.0 ms; repetition time (TR), $5.2 \mathrm{~ms}$; acceleration factor, 3; velocity encoding (VENC), $100 \mathrm{~cm} / \mathrm{s}$; field of view (FOV), $360 \mathrm{~mm} \times 360 \mathrm{~mm}$ spatial resolution, $2.0 \mathrm{~mm} \times 2.0 \mathrm{~mm} \times$ $2.5 \mathrm{~mm}$; temporal resolution, $62.4 \mathrm{~ms}$; phase, 13; and scan time, $11 \mathrm{~min} 20 \mathrm{~s}$. To improve anatomical orientation, cine MR images in coronal views together with 4D flow data were acquired.

\section{Postprocessing}

For the calculation and visualization of $3 \mathrm{D}$ velocity fields, 4D-flow and magnetic resonance angiographic data sets were analyzed using iTFlow (Cardio Flow Design Inc., Tokyo, Japan). The PV planes were defined orthogonal to the vessels at their junction with the left atrium. To visualize the atrial flow patterns, streamlines were emitted from planes 

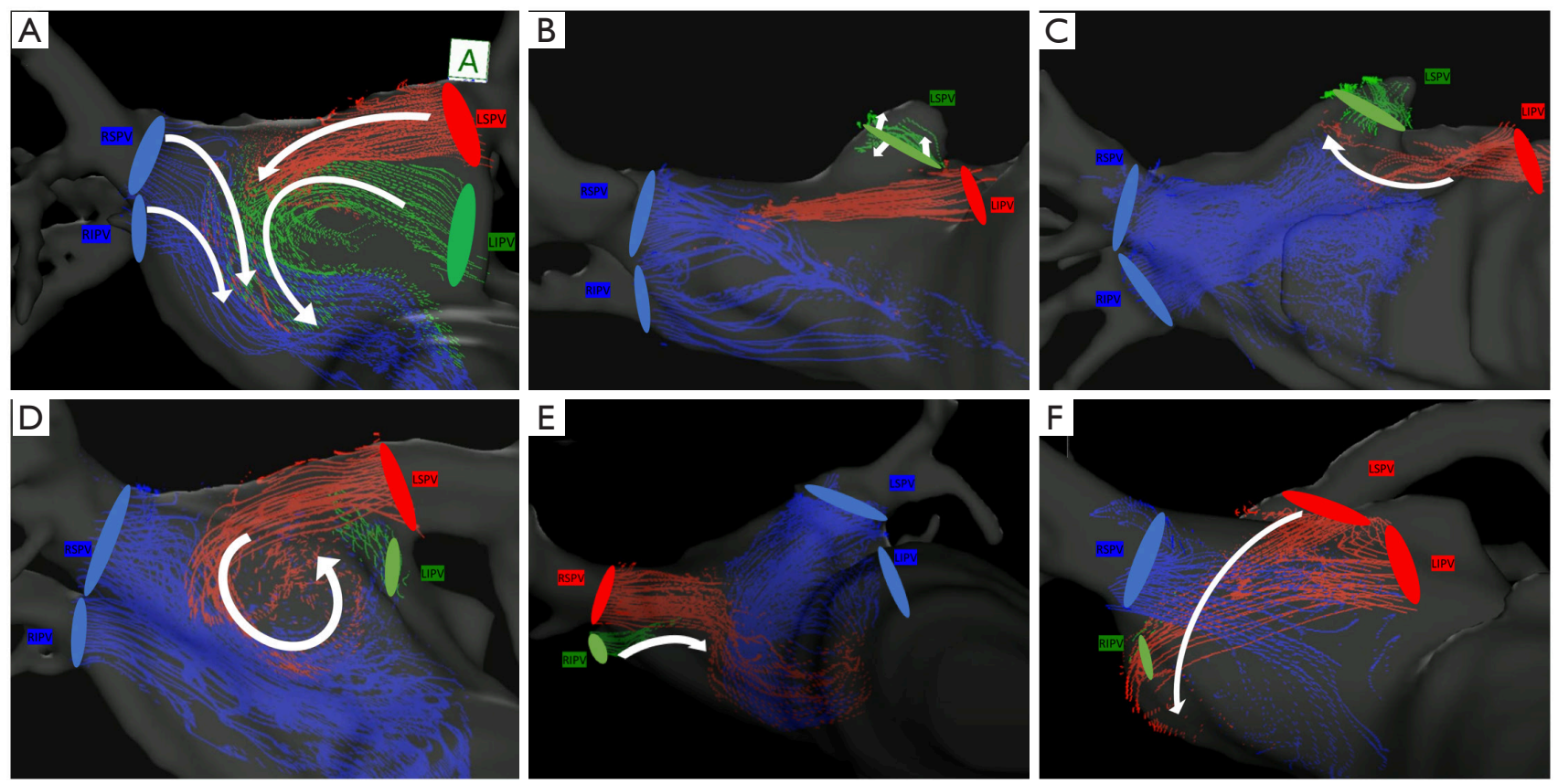

Figure 1 Four-dimensional-flow magnetic resonance imaging of blood flow (arrows) in the left atrium from pulmonary veins in a preoperative patient (A). After lobectomy, five characteristic flow patterns were observed in the left atrium, as shown by representative cases: multidirectional flow (arrows) in a patient undergoing left upper lobectomy with pulmonary vein stapling (B), ascending flow (arrows) in a patient undergoing left upper lobectomy with pulmonary vein ligation (C), recurrent flow (arrows) in a patient undergoing left lower lobectomy with pulmonary vein stapling (D), retracting flow (arrows) in a patient undergoing right lower lobectomy with pulmonary vein stapling (E), and blowout flow (arrows) in a patient undergoing right lower lobectomy with pulmonary vein stapling (F).

placed over each PV. We also evaluated the dynamic change in the flow velocity near the PV stump in each patient by measuring the instantaneous flow velocity at multiple time points during single heart beat (basically, 10 time points per patient). In order to grade the dynamic change of the flow velocity, we calculated the standard deviation of the instantaneous flow velocity values in each patient. We compared the standard deviation of blood flow velocity near the venous stump among each of the lobectomy groups. We also measured the length of the remaining venous conduit after lobectomy on oblique section images because the length of the remaining venous conduit is suspected to be associated with the risk of PV thrombus.

\section{Statistical analysis}

The values were expressed as the mean \pm standard deviation (SD). The unpaired Student's $t$-test was used to test continuous variables. The $\chi^{2}$ test was used to compare categorical variables. A linear regression analysis was performed to determine the relationship between the numerical variables. $\mathrm{P}$ values of $<0.05$ were considered to indicate statistical significance. The Holm-Bonferroni method was used to adjust the $\mathrm{P}$ values in multiple testing. The statistical analyses were performed using the SPSS software program (SPSS statistics version 22, IBM, USA).

\section{Results}

Table 1 shows characteristic variables according to the type of lobectomy (left upper lobectomy versus other lobectomy). There were no remarkable differences in the characteristic variables or operative factors of the two groups (Table 1).

Figure $1 A$ shows a representative blood flow pattern in the left atrium in a preoperative patient (Video 1). Blood flows from the right superior and inferior PV go smoothly to the left ventricle. Likewise, the blood flow from the left superior PV comes into contact with the flows from the right PVs in the left atrium and subsequently goes to the left ventricle. In contrast, blood flow from the left inferior PV goes cranially, forming an eddy stream in the 
Table 2 Blood flow pattern in the left atrium after a lobectomy

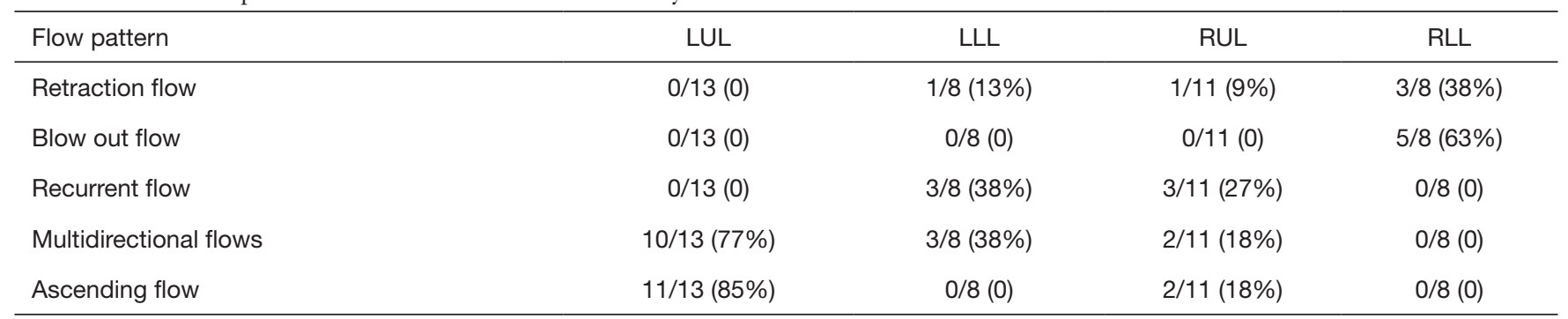

LUL, left upper lobectomy; LLL, left lower lobectomy; RUL, right upper lobectomy; RLL, right lower lobectomy.

atrium before going into the ventricle. These findings were observed in the three patients who underwent 4D-flow MRI preoperatively.

After lobectomy, we found five characteristic flow patterns in the left atrium.

* Multidirectional flow: to-and-fro static blood movement near the PV stump (Figure 1B) (Video 2);

* Ascending flow: head on collision with two venous flows, forming small coil-like flows near the PV stump (Figure 1C) (Video 2);

- Recurrent flow: large eddy blood stream without turbulence in the left atrium (Figure 1D) (Video 2);

* Retracting flow: antegrade movement (washout) of the blood around the vein stump that is accompanied by the neighboring pulmonary venous flow (Figure 1E) (Video 2);

* Blowout flow: blowout of the venous stump by blood streams derived from the diagonally located PV (Figure 1F) (Video 2);

Table 2 shows the incidence of each flow pattern according to the site of resection.

Figure 2 shows the dynamic change in the blood flow velocity $(\mathrm{mL} / \mathrm{s})$ near the venous stump during a single stroke (R-R interval) in each patient. The blood flow velocity near the stump appeared to change extensively after left upper lobectomy, suggesting the development of blood turbulence within the remaining left superior venous conduit (Figure $2 A$ ). According to a quantitative analysis, the standard deviation of the blood flow velocity near the venous stump in patients who had undergone left upper lobectomy was significantly higher than that in each of the other lobectomy groups (Figure 2E).

Figure 3 shows the length of the remaining pulmonary venous conduit after lobectomy. The length of the remaining venous conduit was longest in patients who had undergone left upper lobectomy, with statistically significant differences from each of the other lobectomy groups (Figure 3).
According to a linear regression analysis, the length of the remaining venous conduit was significantly correlated with the standard deviation of the blood flow velocity near the venous stump $(\mathrm{r}=0.671, \mathrm{P}<0.0001)$ (Figure 4).

During the early study period, two patients developed PV thrombus after left upper lobectomy by PV dissection with an endostapler, although both patients recovered without developing cerebral infarction after the administration of anticoagulants. In these two cases, there were no characteristic findings on 4D-flow MRI, or with regard to the length of the remaining venous conduit, and standard deviation of the blood flow near the venous stump (Figure 4). For the purpose of preventing PV thrombus after left upper lobectomy, we ligated the hilar end of the left superior vein in seven patients undergoing left upper lobectomy. Thus, the patients undergoing left upper lobectomy were divided into two subgroups according to the procedure for dissecting left superior PV [stapler alone $(\mathrm{n}=6) v s$. ligation followed by stapling $(n=7)]$. As a result, the length of the remaining venous conduit in the ligation followed by stapling group was significantly shorter than that in the stapling alone group, although the length of the remaining venous conduit after ligation of the left superior PV was still significantly longer than that after other operations (including left lower lobectomy, right upper lobectomy, and right lower lobectomy) (Figure 5A). Likewise, the standard deviation of the blood flow velocity near the venous stump in the ligation followed by stapling group was significantly lower than that in the stapling alone group, although the standard deviation of the blood flow velocity near the venous stump was still significantly higher than that after other operations (including left lower lobectomy, right upper lobectomy, and right lower lobectomy) (Figure 5B).

\section{Discussion}

The incidence of PV stump thrombus after left upper 
A

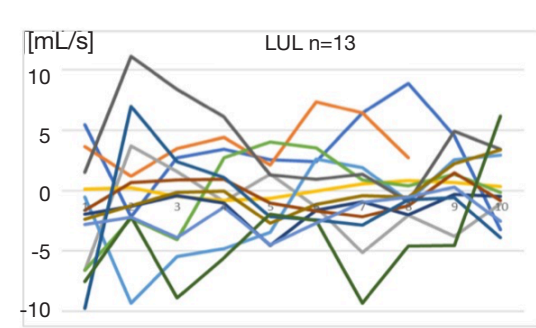

C

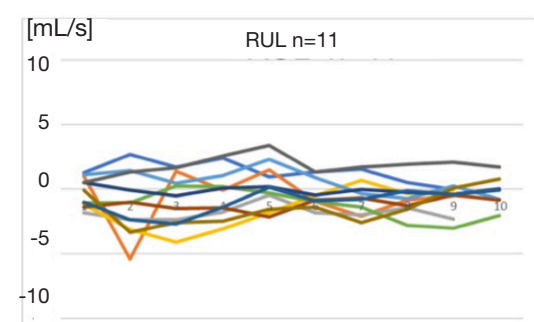

B

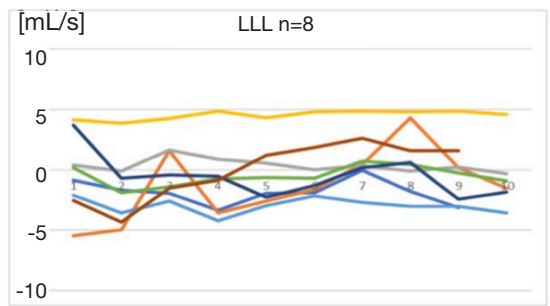

D

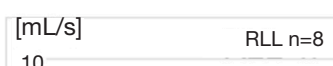

$10 \quad$ RLL $n=8$

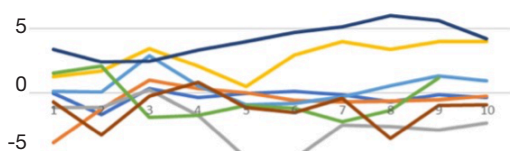

$-5$

$-10$

$\mathrm{P}=0.0064$

$\mathrm{P}=0.0006$

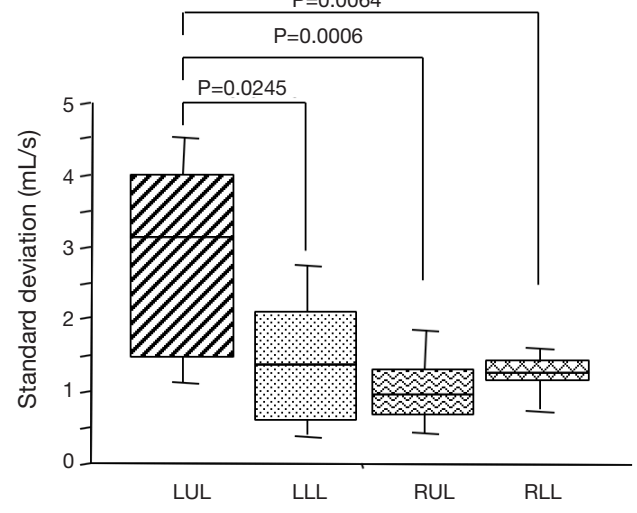

Figure 2 Dynamic change in the blood flow velocity $(\mathrm{mL} / \mathrm{s})$ near the pulmonary venous stump during a single stroke (R-R interval) in patients who underwent left upper lobectomy (LUL) (A), left lower lobectomy (LLL) (B), right upper lobectomy (RUL) (C), and right lower lobectomy (RLL) (D). The blood flow velocity near the stump appears to change extensively after LUL, suggesting the development of blood turbulence within the remaining left superior venous conduit (A). According to a quantitative analysis, the standard deviation of the blood flow velocity near the venous stump in patients who underwent LUL is significantly higher than that in each of the other lobectomy groups (E).

lobectomy ranged from $3.4 \%$ to $17.9 \%(1,11-13)$. PV stump thrombus may be a major cause of arterial infarction of vital organs, including the kidney and brain $(3,12-15)$. According to the relevant literature, the incidence of cerebral infarction after lung cancer surgery is below $1 \%(16,17)$, which is not higher than that after general surgery $(18,19)$. However, in the majority of cases, cerebral infarction occurred after left upper lobectomy, and thus, the incidence of cerebral infarction after left upper lobectomy was $4.2-4.5 \%$, which was significantly higher in comparison to other types of lobar resection $(3,12)$. Because the length of the PV stump after left upper lobectomy was longer than that after any other type of lobectomy, surgeons attempted to reduce the length of PV stump after left upper lobectomy by proximal ligation $(4,5)$. Although proximal ligation of the left superior PV resulted in a significant reduction in the length of PV stump (5), PV stump thrombus still developed in a proportion of patients $(4.1-12.5 \%)$ who had undergone left upper lobectomy $(4,5)$. We used 4D-flow MRI to clarify the differences in the hemodynamic features between patients who had undergone left upper lobectomy and those who had undergone other types of lobectomy. As 


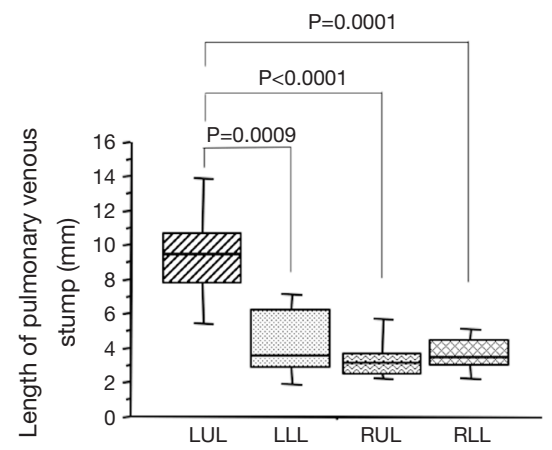

Figure 3 The length of the remaining pulmonary venous conduit after lobectomy according to the types of lobectomy. The length of the remaining venous conduit was longest in patients who had undergone left upper lobectomy (LUL) with statistically significant differences from each of the other lobectomy groups. LLL, left lower lobectomy; RUR, right upper lobectomy; RLL, right lower lobectomy.

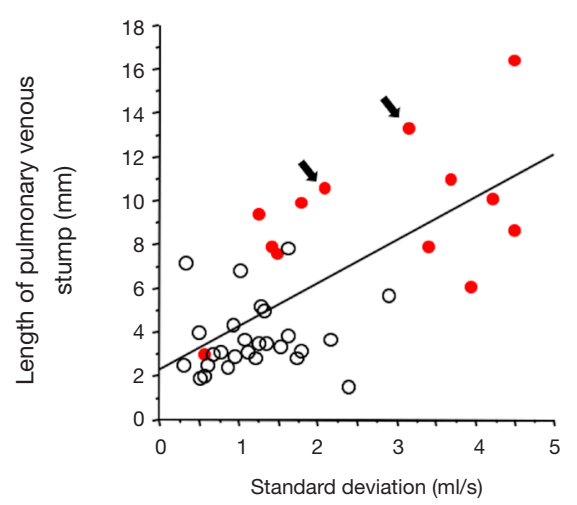

Figure 4 Significant relationship between the length of the remaining venous conduit and the standard deviation of the blood flow velocity near the venous stump $(\mathrm{r}=0.671, \mathrm{P}<0.0001)$. Solid circles; patients who underwent left upper lobectomy, Open circles; patients who underwent lobectomy other than left upper lobectomy, Arrow head; patients who developed pulmonary venous thrombus after lobectomy

a result, we found five characteristic blood stream patterns derived from remaining PVs that had not been found on preoperative 4D-flow MRI (Table 2). The five blood stream patterns could be classified into two groups according to whether the blood streams apparently contributed to washing out the PV stump conduit (thrombus-preventive flow) or apparently contributed to blood turbulence at the
PV stump (thrombus-promotive flow), as below.

* Thrombus-preventive flow includes retracting flow and blowout flow.

* Thrombus-promotive flow includes recurrent flow, multidirectional flow and ascending flow.

As expected, the thrombus-preventive flow patterns were significantly less frequent after left upper lobectomy than after other types of lobectomy [0/13 (0\%) vs. 9/27 (33\%), $\mathrm{P}=0.018]$, while thrombus-promotive flow patterns were more frequent after left upper lobectomy than after other types of lobectomy [12/13 (92\%) vs. 10/27 (37\%), $\mathrm{P}=0.001$ ]. These qualitative findings were strengthened by the quantitative analysis of the hemodynamics around the PV stumps. The blood was found to move extensively around the PV stumps in a to-and-fro manner after left upper lobectomy, suggesting the development of blood turbulence after left upper lobectomy.

We found that blood turbulence at the PV stump could be attenuated by reducing the length of the PV stump by proximal ligation (Figure 5). Considering that the PV stump thrombus did not develop in patients who had undergone proximal ligation in our series, it may be valuable to evaluate the effects of proximal ligation on the incidence of PV stump thrombus after left upper lobectomy in a multi-institutional, prospective study. Several retrospective studies with relatively small study populations have focused on this topic. Nakano et al. reported that PV stump thrombus developed in all patients (4 of 4 patients) who had undergone left upper lobectomy after cutting the PV with a stapler alone, while PV stump thrombus developed in $12.5 \%$ of the patients (1 of 8 patients) who had undergone proximal ligation $(\mathrm{P}=0.01)$ (4). Miyoshi et al. reported that the incidence of PV stump thrombus was only $4.1 \%$ (4 of 98 patients) among patients who had undergone left upper lobectomy with proximal PV ligation (5). Unfortunately, this study did not have control patients in whom the PV had been cut by stapling alone, which compromised the assessment of superiority of proximal ligation over stapling alone. Importantly, they also showed that the PV stump was still significantly longer, even after proximal ligation of the left superior $\mathrm{PV}$, in comparison to the PV stump (other than the left superior PV) after cutting without ligation (5), which was in accordance with our results. Thus, further attempts to reduce the length of the PV stump by intrapericardial ligation of the left superior PV could substantially reduce the incidence of PV stump thrombus, although further risk-benefit assessments are needed to determine whether the procedure should be routinely performed. 

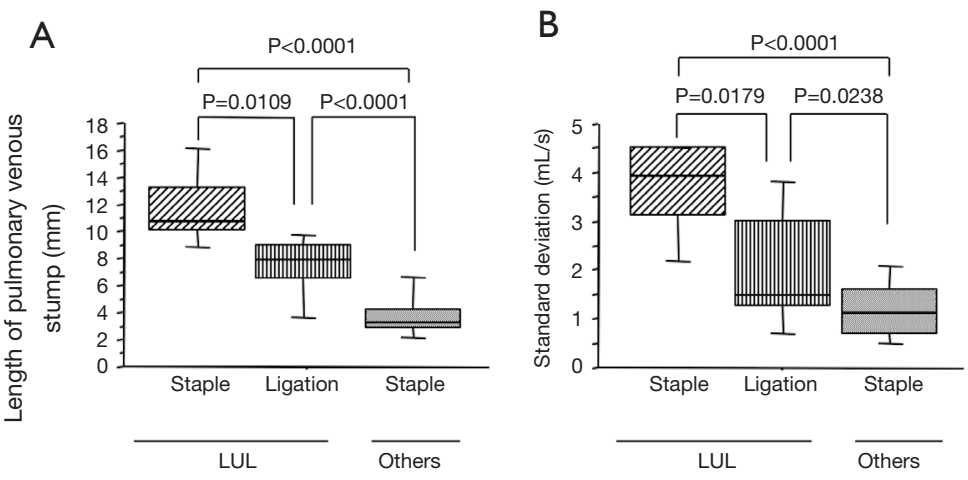

Figure 5 Correlation among patients who underwent left upper lobectomy with division of the left superior pulmonary vein using ligation after stapling, patients who underwent left upper lobectomy with division of the left superior pulmonary vein using stapling alone, and patients who underwent other types of lobectomy with division of the pulmonary vein using stapling alone, with regard to the length of the remaining pulmonary venous conduit after division of the pulmonary vein (A) and the standard deviation of the blood flow velocity near the left superior pulmonary venous stump (B).

Over a century ago, Virchow described three factors that are critically important in the development of venous thrombosis: venous stasis, activation of blood coagulation, and venous intimal damage (20). Thus, patients with supraventricular arrhythmia (which could result in blood stasis or turbulence at the PV stump) and patients with coagulation abnormalities were excluded from the current analysis. With respect to intimal damage, some clinicians may suggest that PV stapling can cause intimal damage because stapled metallic needles are exposed linearly at the venous lumen. However, we do not believe that the venous damage caused by stapling plays an important role in PV stump thrombus formation because of the fact that there have been few reports on PV stump thrombus after stapling at locations other than the left superior PV and because PV stump thrombus can develop more than six months after surgery (13-15), when intimal damage would be expected to be fully resolved.

This is the first report to evaluate the dynamic blood movement to clarify the risk of PV stump thrombus by 4D-flow MRI. The usefulness of the 4D-flow MRI is already proven in the area of cardiovascular diseases (6-9). As shown in this study, we could simultaneously depict three different blood streams and their interaction in the left atrium, which cannot be achieved by other modalities, including cardiac ultrasound, contrast enhanced computed tomography, and perfusion scintigraphy. This non-invasive modality enables detailed qualitative and quantitative assessments of the regional hemodynamics, without requiring radiation exposure or the usage of contrast agents. Because this modality can quantify the regional blood flow, including blood flow of the main pulmonary artery and individual PVs, further study to clarify the usefulness of this modality in preoperative risk assessment for patients with lung cancer and a compromised pulmonary function is warranted.

The present study was associated with several limitations. First, 4D-flow MRI was mainly performed on postoperative day 7. Serial examinations, including examinations in the preoperative and late-postoperative period may reveal more detailed changes in the dynamic blood flow pattern. Second, the sample size was relatively small. Thus, we could not show characteristic findings in two patients with PV stump thrombus formation. Further studies with larger populations may contribute to identifying high-risk patients who require preventive measures, such as postoperative anticoagulant therapy.

In conclusion, our study revealed that left upper lobectomy likely causes blood turbulence near the PV stump through complicated blood streams in the left atrium, which can play a part in the development of PV stump thrombus. In addition, we showed the rationale for recommending proximal ligation of the left superior PV, because a longer PV stump revealed to exacerbate blood turbulence.

\section{Acknowledgments}

Funding: This work was supported by grant-in-aid for scientific research JSPS KAKENHI (JP19K18221). 


\section{Footnote}

Reporting Checklist: The authors have completed the STROBE reporting checklist. Available at http://dx.doi. org/10.21037/jtd-20-1606

Data Sharing Statement: Available at http://dx.doi. org/10.21037/jtd-20-1606

Conflicts of Interest: All authors have completed the ICMJE uniform disclosure form (available at http://dx.doi. org/10.21037/jtd-20-1606). The authors have no conflicts of interest to declare.

Ethical Statement: The authors are accountable for all aspects of the work in ensuring that questions related to the accuracy or integrity of any part of the work are appropriately investigated and resolved. This study was conducted in accordance with the Declaration of Helsinki (as revised in 2013). The study was approved by our institutional review board of No. 190046E and informed consent was taken from all the patients.

Open Access Statement: This is an Open Access article distributed in accordance with the Creative Commons Attribution-NonCommercial-NoDerivs 4.0 International License (CC BY-NC-ND 4.0), which permits the noncommercial replication and distribution of the article with the strict proviso that no changes or edits are made and the original work is properly cited (including links to both the formal publication through the relevant DOI and the license). See: https://creativecommons.org/licenses/by-nc-nd/4.0/.

\section{References}

1. Ohtaka K, Hida Y, Kaga K, et al. Thrombosis in the pulmonary vein stump after left upper lobectomy as a possible cause of cerebral infarction. Ann Thorac Surg 2013;95:1924-8.

2. Ohtaka K, Hida Y, Kaga K, et al. Left upper lobectomy can be a risk factor for thrombosis in the pulmonary vein stump. J Cardiothorac Surg 2014;9:5.

3. Yamamoto T, Suzuki H, Nagato K, et al. Is left upper lobectomy for lung cancer a risk factor cerebral infarction? Surg Today 2016;46:780-4.

4. Nakano T, Kaneda H, Kawamura T, et al. Ligating the pulmonary vein at the pericardial reflection is useful for preventing thrombus formation in the pulmonary vein stump after left upper lobectomy. Gen Thorac Cardiovasc Surg 2019;67:450-6.

5. Miyoshi R, Nishikawa S, Tamari S, et al. Pulmonary vein thrombosis after lobectomy with vein stump closure by ligation. Asian Cardiovasc Thorac Ann 2018;26:546-51.

6. Azarine A, Garçon P, Stansal A, et al. Four-dimensional Flow MRI: Principles and Cardiovascular Applications. Radiographics 2019;39:632-48.

7. van der Geest RJ, Garg P. Advanced Analysis Techniques for Intra-cardiac Flow Evaluation from 4D Flow MRI. Curr Radiol Rep 2016;4:38.

8. Katahashi K, Sano M, Takehara Y, et al. Flow dynamics of type II endoleaks can determine sac expansion after endovascular aneurysm repair using four-dimensional flow-sensitive magnetic resonance imaging analysis. J Vasc Surg 2019;70:107-16.e1.

9. Kamada H, Ota H, Nakamura M, et al. Perioperative Hemodynamic Changes in the Thoracic Aorta in Patients With Aortic Valve Stenosis: A Prospective Serial 4D-Flow MRI Study. Semin Thorac Cardiovasc Surg 2020;32:25-34.

10. von Elm E, Altman DG, Egger M, et al. The Strengthening the Reporting of Observational Studies in Epidemiology (STROBE) Statement: guidelines for reporting observational studies. Int J Surg 2014;12:1495-9.

11. Ichimura H, Ozawa Y, Nishina H, et al. Thrombus formation in the pulmonary vein stump after left upper lobectomy: a report of four cases. Ann Thorac Cardiovasc Surg 2014;20:613-6.

12. Hattori A, Takamochi K, Kitamura Y, et al. Risk factor analysis of cerebral infarction and clinicopathological characteristics of left upper pulmonary vein stump thrombus after lobectomy. Gen Thorac Cardiovasc Surg 2019;67:247-53.

13. Ohtaka K, Hida Y, Kaga K, et al. Pulmonary vein thrombosis after video-assisted thoracoscopic left upper lobectomy. J Thorac Cardiovasc Surg 2012;143:e3-5.

14. Nagaoka E, Yano M, Sugano T, et al. Thrombus in the left superior pulmonary vein after left upper pulmonary lobecotomy. J Thorac Cardiovasc Surg 2008;135:709-10.

15. Gual-Capllonch F, Teis A, Palomeras E. Pulmonary vein spontaneous echocontrast and stroke after pulmonary lobectomy. J Clin Ultrasound 2013;41:321-2.

16. Nojiri T, Inoue $M$, Takeuchi $Y$, et al. Impact of cardiopulmonary complications of lung cancer surgery on long-term outcomes. Surg Today 2015;45:740-5.

17. Matsumoto K, Sato S, Okumura M, et al. Frequency of cerebral infarction after pulmonary resection: A 
multicenter, retrospective study in Japan. Surg Today 2018;48:571-2.

18. Kam PC, Calcroft RM. Peri-operative stroke in general surgical patients. Anaesthesia 1997;52:879-83.

19. Limburg M, Wijdicks EF, Li H. Ischemic stroke after

Cite this article as: Umehara T, Takumi K, Ueda K, Tokunaga T, Harada-Takeda A, Suzuki S, Sato M. Four-dimensional flow magnetic resonance imaging study to explain high prevalence of pulmonary vein stump thrombus after left upper lobectomy. J Thorac Dis 2020;12(10):5542-5551. doi: 10.21037/jtd-20-1606 surgical procedures: clinical features, neuroimaging, and risk factors. Neurology 1998;50:895-901.

20. Brotman DJ, Deither SR, Lip GY, et al. Virchow's triad revisited. South Med J 2004;97:213-4. 